\title{
Fallopian Tube Serous Adenocarcinoma
}

National Cancer Institute

\section{Source}

National Cancer Institute. Fallopian Tube Serous Adenocarcinoma. NCI Thesaurus. Code C40099.

A serous adenocarcinoma that arises from the fallopian tube. It is usually a high grade invasive adenocarcinoma. 